bearings and wear, and a number of other problems which Australia was not equipped to handle, and which the outbreak of war and the expansion of secondary industries had rendered important. Dr. F. P. Bowden was retained by the Council to build up the Section. The University of Melbourne collaborated fully in this work, and laboratory accommodation was provided in the new buildings of the Chemistry Department. During the war years, the section was occupied with a variety of problems, such as the development and manufacture of air. craft bearings; the development of cutting oils, of drawing fluids, of special lubricants and of flamethrower fuels ; studies of cylinder wear, of the wear of producer gas engines, and of the friction and wear in gun barrels; investigations on the detonation of explosives by friction and by impact; the development of equipment for measuring the muzzle velocity of guns at sea, and other work for the Navy, Army and Air Force. It was also engaged in a number of more fundamental investigations, both physical and chemical, which included the study of friction and lubrication. Dr. S. H. Bastow has now taken charge of the Section and a permanent laboratory for it will be built in the University of Melbourne. The Section is maintaining close working collaboration with Dr. Bowden's new research laboratory on the physics and chemistry of rubbing solids in the Department of Physical Chemistry at Cambridge. A joint attack is being made on some problems, and there is an interchange of personnel between the Melbourne and Cambridge laboratories.

\section{Weather Forecasts for Indian Farmers}

AN article in Indian Farming of July 1945 by Dr. L. A. Ramdas describes the preliminary steps that have been taken in the Indian Meteorological Department for the establishment of a service of weather forecasts for Indian farmers. Dr. Ramdas is able to bring to bear on it the experience he has gained as agricultural meteorologist at Poona. The essence of the problem is how to enable Indian farmers and official weather forecasters to co-operate so that farming operations may, so far as is possible, be timed in such a way as to make the best possible use of periods of favourable weather and avoid the worst consequences of unfavourable weather. The official forecaster is often able to supplement the farmer's local knowledge of weather by diagnosing the significance of air movements and changes of cloud over a wide area; but he in turn must know what crops are being grown in different parts of the country and what are the critical periods of their growth and harvest. Here it is the turn of the farmer to help the forecaster. Dr. Ramdas describes fully a long series of questions that have been put to the agricultural departments in the Provinces and the Indian States, and outlines the scheme of wireless forecasts to be used. The forecasting will be done from seven regional centres, and will be broadcast daily by the All India Radio Broadcasting Stations. The scale of the intended system is much greater than that of any seen hitherto in India.

\section{Cauliflower-growing in Britain}

Cauniflowers are the subject of Bulletin No. 131 issued by the Ministry of Agriculture (London: H.M. Stationery Office. 9d. net). Under this title the cultivation in Britain of both winter (broccoli) and summer cauliflowers for market production are discussed in detail, including recommendations as to varieties, soil preparation and manuring, harvesting, packing and marketing. Late varieties of winter cauliflower can be grown successfully in all counties, but the early maturing kinds, which require freedom from severe and sustained frost, are produced chiefly in coastal districts. Summer cauliflowers do best on warm, fertile soils with an adequate water supply. Planning is essential if continuous cutting is to be obtained, and careful selection is needed regarding the sites chosen and varieties grown. To ensure a crop ready for cutting in June, a special technique is required involving the use of frames, full details of which are supplied. Information is also provided concerning the type of cauliflowers suitable for pickling or brining, and also the production of the now popular Cape broccoli, which matures in late March or April when other vegetables are scarce. Control measures for a number of pests and diseases are given, and the bulletin concludes with a description of local practices, so that the long experience of large-scale growers may be available to all.

\section{Treatment of Lupus by Calciferol}

THE treatment of lupus by calciferol, described by Drs. G. B. Dowling and E. W. Prosser Thomas in the Lancet and noted in Nature of March 2, p. 260, is the subject of a comment by Dr. Jacques Charpy in the Lancet of March 16, p. 400. Dr. Charpy says that he has used similar treatment since 1941, and that he made his first report on twenty-seven subjects treated in this way on July 3, 1943; this form of treatment has been known in France since 1943 as the 'Charpy treatment'. Intolerance of the calciferol used in France has "hardly ever" been noted, because it is chemically pure and perhaps because it is made up in alcoholic solution and not in oil. Dr. Charpy says that lupus vulgaris has almost completely disappeared from France since 1941. Further information is given by Dr. Dowling in the Lancet (590, April 20, 1946).

\section{Diffusion Pump Oils}

THERE has long been a need for a diffusion pump oil which, while hot, would withstand atmospheric pressure without bad effects. G. P. Brown (Rev. Sci. Inst.,16, 316; Nov. 1945) has found that certain members of the family of silicones are stable under the above conditions and also have vapour pressures as low as, or lower than, the best commercial oils available. Comparative performances of a straight hydrocarbon oil ('Litton C'), an ester ('Octoil'), a chlorinated aromatic hydrocarbon oil ('Narcoil') and two typical silicones in a 6-in. non-fractionating unbaffled allmetal diffusion pump are presented. Tests show that the highest vacuum is produced by the high-boiling silicone (b.p. $430^{\circ}$ C.) and that the silicone is nearly completely resistant to oxidation when exposed to air while hot.

\section{High-Voltage Overhead Lines of the British Grid}

A PAPER read in London on November 14 before the Institution of Electrical Engineers, by W. J. Nicholls, reviews the progress that has taken place in the past fifteen years in the design of the steel. tower high-voltage transmission lines of the Central Electricity-Board in Britain. Lines operating at $132 \mathrm{kV}$. are dealt with separately from those operating at $66 \mathrm{kV}$. and $33 \mathrm{kV}$. Changes in conductors, joints, insulators and towers have been made in the light of experience, and a record of these is given as well 